\title{
The Aggregate Implications of Size-Dependent Distortions
}

Nicolas Roys

This article examines the aggregate implications of size-dependent distortions. These regulations misallocate labor across firms and hence reduce aggregate productivity. The author then considers a case study of labor laws in France, where firms with 50 employees or more face substantially more regulation than firms with fewer than 50 . The size distribution of firms is visibly distorted by these regulations: There are many firms with exactly 49 employees. A quantitative model is developed with a payroll tax of 0.15 percent that applies only to firms with more than 50 employees. Removing the regulation while holding total employment constant leads to an increase in output of around 0.3 percent. (JEL E23, O1, O40)

Federal Reserve Bank of St. Louis Review, First Quarter 2018, 100(1), pp. 73-85. https://doi.org/10.20955/r.2018.73-85

\section{INTRODUCTION}

In the United States, new firms created 2.9 million jobs per year on average over the period 1980-2010. 1 While new firms clearly play an important role in job creation, many fail after a short period of time or do not grow. Are regulations preventing young businesses from expanding? Many regulators seem to think so: In many countries small firms face lighter regulation than large firms. The rationale for exempting small firms from some regulations is that the compliance cost is too high relative to their sales. A necessary consequence, however, is that regulations are phased in as the firm grows, generating an implicit marginal tax. Because regulations are typically phased in at a few finite points, they are sometimes referred to as "threshold effects."

Regulation, broadly defined, takes many forms-from hygiene and safety rules, to mandatory elections of employee representatives, to larger taxes. Under the Affordable Care Act, firms with 50 or more full-time equivalent employees are required to offer health insurance to their full-time employees. This requirement raises concerns that firms cut employment to

Nicolas Roys was an economist at the Federal Reserve Bank of St. Louis and is a senior lecturer at Royal Holloway, University of London. This Review article relates to Gourio and Roys (2014). The author thanks Joseph McGillicuddy for excellent research assistance.

(C) 2018, Federal Reserve Bank of St. Louis. The views expressed in this article are those of the author(s) and do not necessarily reflect the views of the Federal Reserve System, the Board of Governors, or the regional Federal Reserve Banks. Articles may be reprinted, reproduced, published, distributed, displayed, and transmitted in their entirety if copyright notice, author name(s), and full citation are included. Abstracts, synopses, and other derivative works may be made only with prior written permission of the Federal Reserve Bank of St. Louis. 
Figure 1

Distribution of French Firms with 20 to 100 Employees

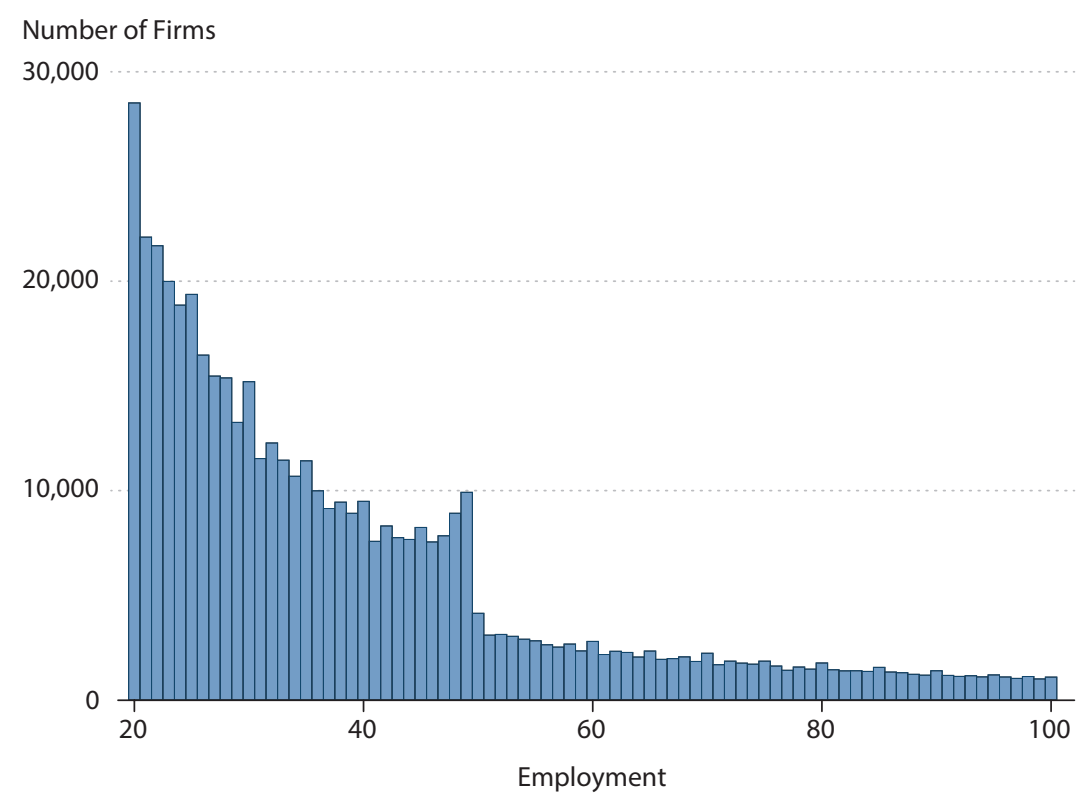

SOURCE: INSEE, BRN.

stay below the threshold or substitute some of their full-time workers with part-time workers. Similarly, regulations that alter the incentives to expand explain the large number of small community banks in the United States.

These distortions have attracted attention in public policy circles. The common wisdom, as reflected in numerous reports by blue-ribbon panels, is that these regulations significantly impede the growth of small firms and should be suppressed or smoothed out. However, there is little work formally modeling these policies to understand and evaluate their effects. This article proposes a simple model and gives a quantitative evaluation of this common wisdom. What are the potential benefits of removing, or smoothing, the regulation thresholds? To answer this question, this article considers a case study of regulations that apply only to firms in France with more than 50 employees. The firm-size distribution is distorted: There are few firms with exactly 50 employees and a large number of firms with 49 employees. Figure 1 plots the firm-size distribution in our French data, illustrating this well-known pattern. The visibly distorted firm distribution suggests that productivity could be increased if firms close to the threshold grow, as labor would be reallocated toward more-productive firms. Because these regulations depend on a precise threshold, the behavior of firms around the threshold is particularly informative on the effects of distortions.

The rest of the article proceeds as follows. Section 2 presents a model to study regulations that limit firm scale. Section 3 presents a case study of labor laws in France that differ depend- 
ing on the side of the employment threshold firms stand on. Section 4 applies the model of Section 2 to study these distortions. Section 5 proposes a quantitative analysis. Section 6 concludes.

\section{THE MODEL}

This section introduces a simple model of production and employment, based on Lucas (1978), to evaluate the impact of size-dependent distortions.

\subsection{Environment}

There is a continuum of firms with production function

$$
y=e^{z} n^{\alpha}
$$

where $n$ is employment and $e^{z}$ is a firm's productivity level ( $e$ denotes the exponential function). The distribution of productivity in the population is characterized by the density $f$. Production displays decreasing returns $\alpha \in(0,1) . \underline{2}$ Aggregate output, $Y$, is defined as the integral of the production of each firm $y(z)$,

$$
Y=\int e^{z} n(z)^{\alpha} f(z) d z
$$

where $n(z)$ is the employment of firms with productivity $z$.

Firms hire labor in a competitive labor market where workers supply labor inelastically. Let total employment be denoted by $N$. The wage rate, $w$, taken as given by each firm, is such that the labor market in equilibrium is

$$
\int n(z) f(z) d z \leq N
$$

Labor costs for the firm are equal to the wage bill multiplied by a size-dependent $\operatorname{tax} T(n)$.

\subsection{Labor Demand}

A firm with productivity $z$ solves the optimization problem,

$$
\max _{n}\left\{e^{z} n^{\alpha}-w n(1+T(n))\right\} .
$$

If $T$ is differentiable, labor demand satisfies the first-order condition,

$$
\alpha e^{z} n^{\alpha-1}=w\left(1+T(n)+n T^{\prime}(n)\right) .
$$

If $T(n)=\tau$, distortions are size independent and the first-order condition simplifies to $\alpha e^{z} n^{\alpha-1}=w(1+\tau)$. The following functional form will be used for the remainder of this section:

$$
T(n)=n^{\tau}-1
$$


Figure 2

Taxes, Employment, and Productivity

\section{A. Taxes and Employment}

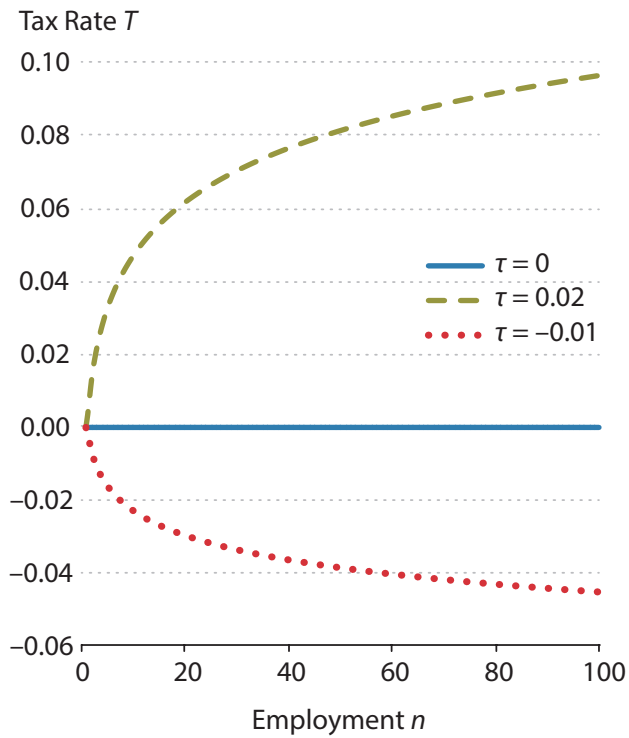

\section{B. Log Employment and Productivity}

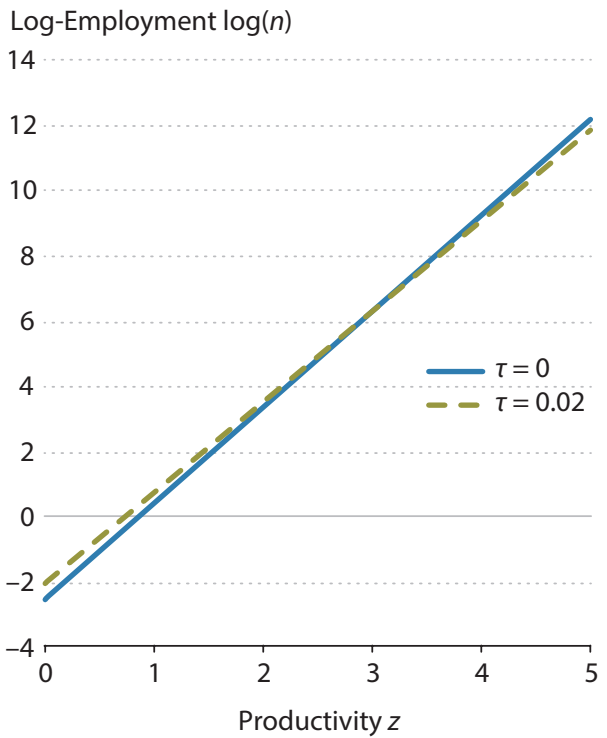

NOTE: The relations plotted in the right panel were calculated by assuming the distribution of productivity is exponential with rate parameter 3.2 , setting the curvature parameter to 0.66 , and normalizing the labor supply to 1 .

Panel A of Figure 2 displays this tax function for different values of $\tau$. If $\tau=0$, there are no distortions. If $\tau>0$, distortions are size dependent, and larger establishments face higher distortions than smaller ones. For instance, with $\tau=0.02$, the tax rate for firms with fewer than 20 employees is at most 6 percent, while the tax rate for firms with more than 100 employees is close to 10 percent.

Labor demand can be solved in closed form:

$$
n=\left(\frac{\alpha e^{z}}{w(1+\tau)}\right)^{\frac{1}{1-\alpha+\tau}}
$$

With distortions, the link between employment and productivity becomes weaker. Moreproductive firms are relatively smaller and less-productive firms are relatively larger compared with the baseline scenario with no distortions, as Panel B of Figure 2 shows.

\subsection{Aggregates}

Using labor demand (equation (3)) and the resource constraint (equation (2)), the equilibrium wage rate $w$ can be expressed as

$$
(1+\tau) w=\alpha\left(N^{-1} \int e^{\frac{z}{1-\alpha+\tau}} f(z) d z\right)^{1-\alpha+\tau}
$$


Figure 3

Productivity Losses and Distortions

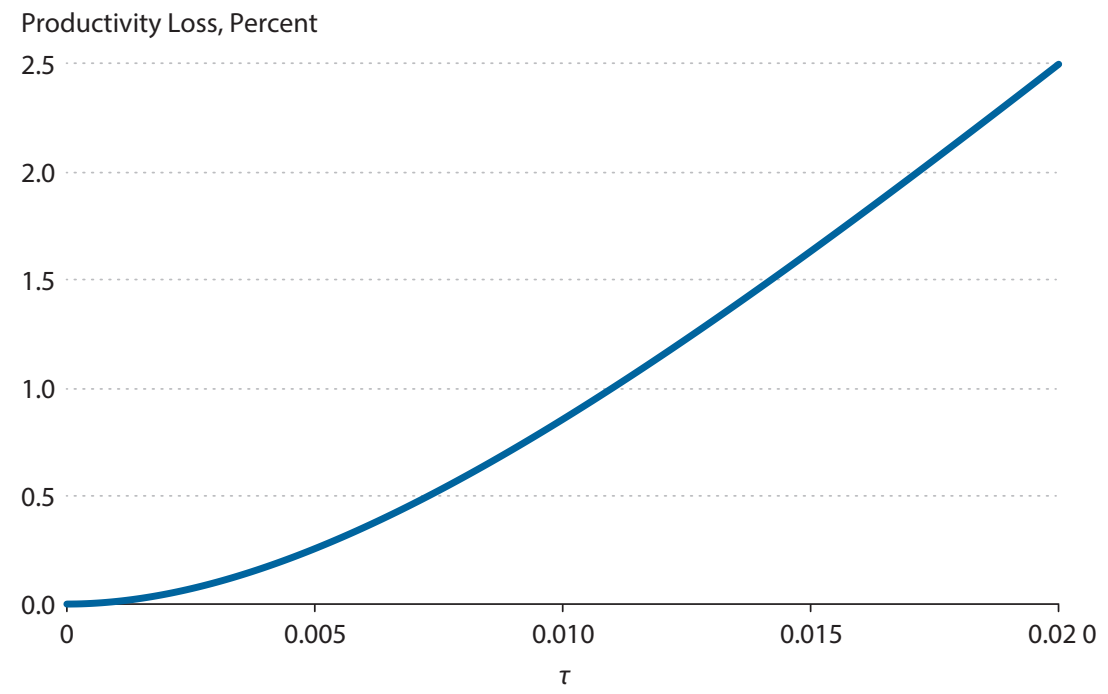

Using the equilibrium wage rate and inserting labor demand in equation (1), aggregate output, $Y$, can be characterized in closed form:

$$
Y=\left(\int e^{\frac{z}{1-\alpha+\tau}} f(z) d z\right)^{-\alpha}\left(\int e^{\frac{z(1+\tau)}{1-\alpha+\tau}} f(z) d z\right) N^{\alpha}
$$

It is a Cobb-Douglas function in aggregate employment and a productivity index. The productivity index is a weighted average of the productivity level of each firm in the economy.

How should the planner allocate labor across firms to maximize aggregate output, $Y$ ? It corresponds to the competitive equilibrium when $\tau=0$. Then, aggregate output simplifies to

$$
Y=\left(\int e^{\frac{z}{1-\alpha}} f(z) d z\right)^{1-\alpha} N^{\alpha} .
$$

Further, when $\tau=0$, the first-order condition of each firm is

$$
\alpha e^{z} n^{\alpha-1}=w .
$$

The efficient allocation equates marginal products $\alpha e^{z} \eta^{\alpha-1}$ across all firms. In other words, without distortions, high-productivity firms and low-productivity firms have the same marginal productivity of labor. In the distorted economy, there is dispersion across firms in average labor productivity. Formally, average labor productivity is

$$
\frac{y}{n}=\left(\frac{w(1+\tau)}{\alpha}\right)^{\frac{1-\alpha}{1-\alpha+\tau}} e^{\frac{\tau z}{1-\alpha+\tau}} .
$$


How large are the output losses due to these distortions? Assume the distribution of productivity is exponential: $f(z)=3.2 e^{-3.2 z}, \forall z \in[0, \infty)$. The curvature parameter $\alpha$ is set to 0.66 . And labor supply is normalized to 1 . Figure 3 reports the output loss (in percent) for different values of $\tau$. The upper bound of $\tau=0.02$ corresponds to a tax rate of about 10 percent for a firm with 100 employees. One can see that distortions can lead to GDP losses of up to 2.5 percent.

\section{SIZE-DEPENDENT REGULATIONS IN FRANCE}

The previous section shows that the output losses due to distortions can potentially be large. It also raises the question of how large these distortions are in the real world. The rest of the article is devoted to quantifying the effect of a particular distortion. It is a case study of the impact of distortions on productivity that looks at size-dependent regulations in France. Because these regulations depend on a precise threshold, the behavior of firms around the threshold is particularly informative on the effects of distortions.

\subsection{Institutional Background}

Labor laws in France as well as various accounting and legal rules make special provisions for firms with more than 10,11,20, or 50 employees. These regulations, however, are not all based on the same definition of "employee." Labor laws, which are likely the most important, are based on the full-time equivalent workforce. The full-time equivalent workforce is computed as an average of a firm's workforce over the past 12 months, including part-time workers and temporary workers but not trainees or contrats aidés (a class of government-subsidized, limited-duration contract workers, which may include people that face "special difficulties" in finding employment, such as the very long-term unemployed or unskilled youth). Hence, it seems fairly difficult for firms to work around the regulations. The main additional regulations as the firm reaches 50 employees are

- possible mandatory designation of an employee representative;

- formation and training of a committee for hygiene, safety, and work conditions;

- formation of a comité d'entreprise (works council) that must meet at least every other month, have some office space, and receive a subsidy equal to 0.2 percent of the total payroll and that has both social objectives (e.g., organizing cultural or sports activities for employees) and an economic role (mostly on an advisory basis);

- a higher payroll tax rate, which increases from 0.9 percent to 1.5 percent, to subsidize training (formation professionelle); and

- if more than nine workers are fired for "economic reasons," a special legal process must be followed (plan social), which increases dismissal costs and creates legal uncertainty for the firm.

This list is not exhaustive, but clearly one would expect the costs of these regulations to be significant. Some of these costs are also difficult to model in a tractable manner. In some cases-in particular, the comité d'entreprise - the firm is required to fund additional worker 


\section{Table 1}

\section{Distribution of French Firms with 40 to 59 Employees}

\begin{tabular}{|c|c|c|c|c|c|c|c|}
\hline Employees & Fraction & S.E. & No. of Firms & Employees & Fraction & S.E. & No. of Firms \\
\hline 40 & 8.42 & 0.28 & 9,486 & 50 & 3.67 & 0.29 & 4,140 \\
\hline 41 & 6.72 & 0.29 & 7,575 & 51 & 2.75 & 0.29 & 3,097 \\
\hline 42 & 7.38 & 0.29 & 8,311 & 52 & 2.78 & 0.29 & 3,130 \\
\hline 43 & 6.88 & 0.29 & 7,752 & 53 & 2.70 & 0.29 & 3,040 \\
\hline 44 & 6.81 & 0.29 & 7,666 & 54 & 2.57 & 0.29 & 2,901 \\
\hline 45 & 7.31 & 0.29 & 8,239 & 55 & 2.51 & 0.29 & 2,826 \\
\hline 46 & 6.70 & 0.29 & 7,548 & 56 & 2.34 & 0.29 & 2,638 \\
\hline 47 & 6.96 & 0.29 & 7,841 & 57 & 2.24 & 0.29 & 2,526 \\
\hline 48 & 7.92 & 0.29 & 8,916 & 58 & 2.37 & 0.29 & 2,670 \\
\hline 49 & 8.80 & 0.28 & 9,916 & 59 & 2.08 & 0.29 & 2,344 \\
\hline
\end{tabular}

SOURCE: INSEE, BRN

NOTE: Fraction is the number of firms for each employment size (40 to 59 employees) divided by the total number of firms with 40 to 59 employees; S.E. is the associated standard error; and No. of Firms is the raw number of firms in each bin.

benefits. To the extent that the process is reasonably efficient, these rules might simply amount to a substitute form of compensation and have limited effects: The higher benefits may allow firms to attract better workers or to pay them less.

\subsection{Data}

The data come from a panel of firms assembled by the French National Institute of Statistics and Economic Studies (INSEE) that covers the 1994-2000 period. This panel, known as BRN (Bénéfices Réels Normaux), contains employment and standard accounting information on total compensation costs, value added, current operating surplus, gross productive assets, etc. The BRN data include all private companies in France with a sales turnover of more than 3.5 million francs (around 530,000 euros) and liable to corporate taxes under the standard regime. These data also include some other smaller firms. The 3.5 million threshold implies that all firms with more than 30 employees or so are included. Hence, I focus on the threshold at 50 employees, for which the data are essentially exhaustive. When I estimate the model, I remove from the sample firms with strictly fewer than 20 employees. This generates a sample of 44,189 firms that we follow for 7 years, or 309,323 firm-year observations.

Figure 1 plots the distribution of employment for the entire period (1994-2000), truncating at 100 employees. There is clearly a large discontinuity around the threshold of 50 employees. Many surveys reveal "rounding" of employment, but this figure shows the opposite pattern.

Table 1 reports the distribution of firms with 40 to 59 employees. There is a clear drop in the number of firms after 49 employees. For example, there are more than three times as many firms with 49 employees as firms with 51 employees. 


\section{MODEL APPLICATION}

I apply the model of Section 2 to the case of size distortions in France. I replace the smooth function $T$ with a step function to mimic the regulations described in the previous section. Firms face a regulation that requires them to pay a higher proportional tax on wages $\tau$ if they currently have more than $\underline{n}$ employees. Formally, if $n$ is greater than $\underline{n}$, a proportional payroll $\operatorname{tax} \tau$ applies. The proportional tax applies to all employment, including that below $\underline{n}$. For simplicity, there is only one threshold and $\underline{n}=50$.

\subsection{Labor Demand}

Take a firm that operates below the threshold. The firm solves the following problem:

$$
\pi(z)=\max _{0 \leq n<\underline{n}}\left\{e^{z} n^{\alpha}-w n\right\} .
$$

There is some value of $z$, say $\underline{z}$, such that the firm's optimal labor demand equals $\underline{n}$ when the restriction $n<\underline{n}$ is ignored. Note that $n(z)$ is strictly increasing in $z$ absent any restrictions on $n$. Thus, if $z$ is below $\underline{z}$, the firm will hire $n(z)=\left(\frac{\alpha}{w}\right)^{\frac{1}{1-\alpha}} e^{\frac{z}{1-\alpha}}<\underline{n}$ employees and receive profit $\pi(z)=e^{\frac{z}{1-\alpha}}\left(\frac{\alpha}{w}\right)^{\frac{\alpha}{1-\alpha}}(1-\alpha)$. If $z$ is greater than or equal to $z$, the best the firm can do is hire right at (or just below) the threshold due to the restriction $n<\underline{n}$. In this case, optimal labor demand is $n(z)=\underline{n}^{-}$(where $\underline{n}^{-}$indicates a value just below $\underline{n}$ ) and the firm receives profit $\pi(z)=e^{z} \underline{n}^{\alpha}-w \underline{n}$.

There is some point, though, where a firm's productivity is great enough such that it would be more profitable to operate above the threshold and pay the higher proportional tax on wages $\tau$ than to operate just below the threshold and avoid the additional tax. A firm that operates above the threshold solves the following problem:

$$
\pi(z)=\max _{n \geq \underline{n}}\left\{e^{z} n^{\alpha}-w(1+\tau) n\right\} .
$$

Call the value of $z$ for which a firm is indifferent between operating above and below the threshold as $\bar{z} \cdot \bar{z}$ is defined as the solution to

$$
e^{\frac{z}{1-\alpha}}\left(\frac{\alpha}{w(1+\tau)}\right)^{\frac{\alpha}{1-\alpha}}(1-\alpha)=e^{z} \underline{n}^{\alpha}-w \underline{n} .
$$

If a firm has productivity $z>\bar{z}$, it operates above the threshold, selecting optimal employment $n(z)=\left(\frac{\alpha}{w(1+\tau)}\right)^{\frac{1}{1-\alpha}} e^{\frac{z}{1-\alpha}}>\underline{n}$ and receiving profit $\pi(z)=e^{\frac{z}{1-\alpha}}\left(\frac{\alpha}{w(1+\tau)}\right)^{\frac{\alpha}{1-\alpha}}(1-\alpha)$. If $z$ is less than or equal to $\bar{z}$, then the firm operates below the threshold, making decisions as described in the preceding paragraph. It is easy to see that $\bar{z}>\underline{z}$, provided that there is a cost of operating above the threshold $\tau w \underline{n}>0$. 
Figure 4

Distribution of French Firms with 40 to 59 Employees, Model Without Measurement Error

Frequency

0.4

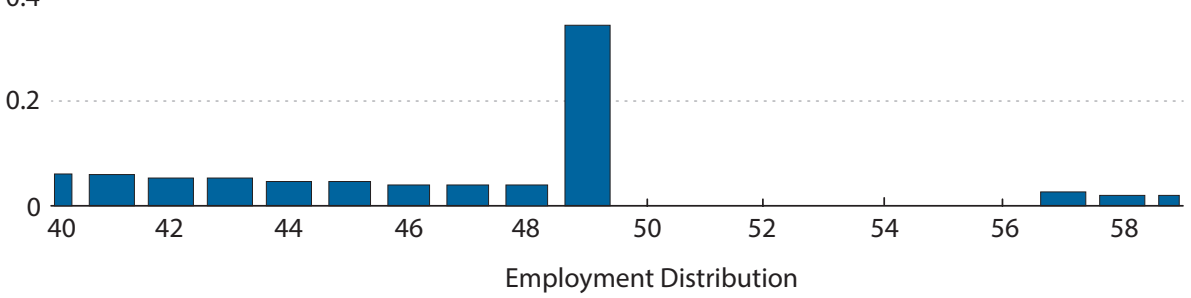

To obtain the formula for the profit of a firm with productivity $z$, note the following summary of the above results: (i) if $z<\underline{z}$, the firm will earn more profit below the threshold than above since the firm pays lower wages; (ii) if $z>\bar{z}$, the firm will decide to operate above the threshold; and (iii) if $z \in[z, \bar{z}]$, it is optimal for the firm to remain just below the threshold. Hence,

$$
\pi(z)=\left\{\begin{array}{l}
e^{\frac{z}{1-\alpha}}\left(\frac{\alpha}{w}\right)^{\frac{\alpha}{1-\alpha}}(1-\alpha) \text { for } z<\underline{z}, \\
e^{z} \underline{n}^{\alpha}-w \underline{n} \text { for } \underline{z} \leq z \leq \bar{z}, \\
e^{\frac{z}{1-\alpha}}\left(\frac{\alpha}{w(1+\tau)}\right)^{\frac{\alpha}{1-\alpha}}(1-\alpha) \text { for } z>\bar{z}
\end{array}\right.
$$

For completeness, I also state the employment demand:

$$
n(z)=\left\{\begin{array}{l}
\left(\frac{\alpha}{w}\right)^{\frac{1}{1-\alpha}} e^{\frac{z}{1-\alpha}} \text { for } z<\underline{z}, \\
\underline{n}^{-} \text {for } \underline{z} \leq z \leq \bar{z}, \\
\left(\frac{\alpha}{w(1+\tau)}\right)^{\frac{1}{1-\alpha}} e^{\frac{z}{1-\alpha}} \text { for } z>\bar{z} .
\end{array}\right.
$$

Overall, firms are distributed above and below the threshold and bunched just below the threshold.

\subsection{Firm Distribution}

Firm productivity, $z$, has an exponential distribution with parameter $\lambda$. Since log employment is proportional to $z$, employment follows a Pareto distribution with parameter 


\section{Table 2}

\section{Economic Parameters}

\begin{tabular}{cll} 
Parameters & Values & \multicolumn{1}{c}{ Definition } \\
\hline$a$ & 0.66 & Curvature profit function \\
$\sigma_{m r n}$ & 0.0324 & Measurement error \\
$\tau$ & 0.0015 & Payroll tax above $\underline{n}$ \\
$\lambda$ & 3.6829 & Exponential distribution \\
\hline
\end{tabular}

\section{Table 3}

\section{Moments}

\begin{tabular}{|c|c|c|}
\hline & Data & Model \\
\hline Standard deviation $\Delta \log n$ & 0.1561 & 0.1561 \\
\hline Power law coefficent & 2.2522 & 2.2522 \\
\hline \multicolumn{3}{|l|}{ Density of firms in each bin } \\
\hline $40-46$ & 0.0718 & 0.0666 \\
\hline $47-49$ & 0.0790 & 0.0783 \\
\hline $50-52$ & 0.0307 & 0.0341 \\
\hline $53-59$ & 0.0240 & 0.0281 \\
\hline
\end{tabular}

$\beta=\lambda(1-\alpha)+1 . \underline{3}$ Figure 4 displays the firm-size distribution implied by the model around the threshold. There is a substantial "hole" in the distribution, with no firms whatsoever between 50 and 55 employees. This is an empirical challenge, because in the data there are many firms with an employment level slightly greater than 49 . I attribute the presence of all these firms to measurement error.

\section{QUANTITATIVE ANALYSIS}

This section proposes a simple calibration of the model and evaluates the aggregate effect of the distortions described in the previous section.

\subsection{Calibration}

Table 2 lists the calibrated values of the parameters. I incorporate measurement error in $(\log )$ employment. Formally, measured employment is equal to the product of the true value and a lognormal error term, with standard deviation $\sigma_{m r n}$ and a mean equal to unity. Measurement error also helps capture model misspecification, which can take several forms. First, the measure of employment is the arithmetic average of the number of employees at the end of each quarter. This is the relevant measure of employment for some but not all of the regulations. Some regulations apply based on employment measured as the full-time equivalent 
Figure 5

\section{Distribution of French Firms with 40 to 59 Employees}

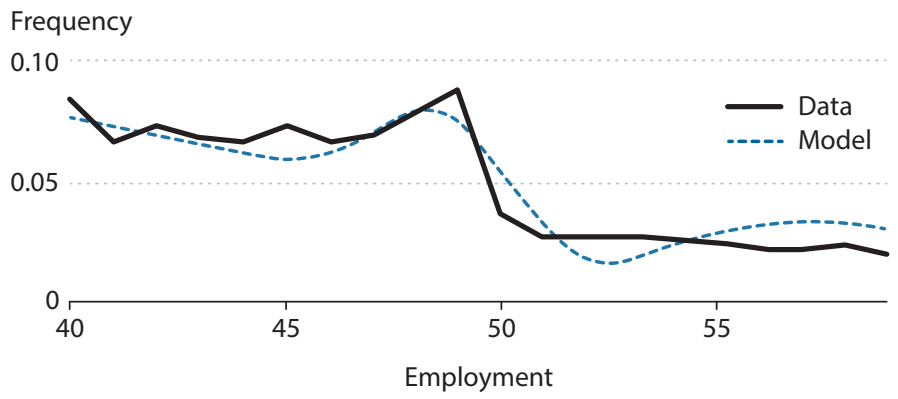

NOTE: The distributions are normalized by the total number of firms with 40 to 59 employees.

workforce, and others apply if there are more than 50 employees in the firm for more than 12 months. Second, measurement error also captures adjustment costs or search frictions, which lead to an imperfect control of the size of the workforce.

The wage rate is normalized to 1 . The curvature parameter $\alpha$ is set to 0.66 . This last parameter is a reduced form for the labor share, decreasing returns to scale, and the elasticity of demand.

Table 3 lists the target moments: (i) the volatility of growth in employment and the slope of the power law and (ii) the distribution of employment around the threshold, as approximated by the density of firms with 40 to 46 employees, 47 to 49 employees, 50 to 52 employees, and 53 to 59 employees. 4 The rational for the first group of moments (i) is that I want the model to be consistent with key features of firm dynamics. The rationale for the distribution of employment around the threshold (ii) is that I want to reproduce well the discontinuity in the firm-size distribution, which is the prima facie evidence that the regulation matters.

Table 3 evaluates the fit of the model. Overall, the data are consistent with a small but significant proportional payroll tax of 0.15 percent. This value is lower than the taxes that are actually set in the law, which presents an apparent puzzle. One possible interpretation is that some of these regulations are indeed not as costly as they appear and represent benefits that are valued by workers. The model requires a measurement error of around 3 percent, or on average two workers around the threshold. In spite of its parsimony, the model is able to reproduce reasonably well all the targeted moments and, in particular, the discontinuities in the distributions. A graphical illustration is provided in Figure 5.

\subsection{Policy Experiments}

I use the calibrated model to infer the aggregate effect of the regulation on productivity. The results are reported in Table 4. From the point of view of a social planner, the regulation misallocates labor across firms and hence reduces aggregate productivity. I now perform the same calculation as in Section 2. Precisely, I ask how much of an increase in output can be 


\section{Table 4}

Policy Experiments

\begin{tabular}{lc} 
Experiment & Gains (\%) \\
\hline Benchmark & 0.30 \\
Apply regulation to all firms & -2.50 \\
Apply regulation to firms above 75 employees & 0.06
\end{tabular}

NOTE: Gains are relative to the scenario when the regulation is applied to firms with more than 50 employees.

obtained, holding total employment constant, by reallocating labor across firms.

The gain in total output, holding total labor constant, is 0.30 percent, which is significant. Second, one might ask how much of the efficiency gain can be achieved by extending the threshold to 75 employees rather than 50 . The answer is, not much: The gains are reduced to 0.06 percent. Third, the motivation for the phase-in of the regulation at 50 employees is that it is too costly to impose the compliance cost on small firms. I evaluate this argument by considering the counterfactual: What would happen if all firms were subject to the regulation? It would reduce output by 2.5 percent. It is safe to say, then, that applying the regulation to all firms would be quite costly, which suggests that the phase-in is perhaps not such a bad policy.

\section{CONCLUDING REMARKS}

This article studies a particular regulation that clearly distorts the firm-size distribution, leading to an obvious misallocation of labor-a channel that has been emphasized in the recent literature. The model fits the size-distribution discontinuity around the threshold well. Removing the regulation leads to an increase of output close to 0.3 percent, holding employment fixed.

These results suggest that size distortions have a fairly moderate aggregate impact. What can explain the small benefits in Section 5 with the potentially large benefits in Section 2? Further research is needed to conclusively address the issue. There are at least three reasons to believe the effects could be bigger. First, this is just one example of distortions among many others. France is characterized by, for instance, stringent employment-protection legislation, and more than 15 percent of workers are affected by minimum wage increases. Second, the model abstracts from the notion of match quality and assortative matching. It might be missing some of the negative effects of the regulation. For instance, some talented workers might be stuck in small unproductive firms because of the regulation but would contribute more to aggregate output by working in larger firms. Last, the proposed framework is static and there may be dynamic effects of these policies that are missed by the current analysis. These distortions reduce the value of investment and the value of entry. 


\section{NOTES}

1 See Decker et al. (2014).

2 This formulation is equivalent to a linear production technology, where firms have some market power. In this case, $a<1$ is equal to the inverse of the demand elasticity.

3 Many studies have found that this is a good approximation of the firm-size distribution. See Gabaix (2016) for a review of power law in economics.

4 The distribution is the number of firms in each bin, divided by the length of the bin (7 or 3), and further divided by the total number of firms with 40 to 59 employees.

\section{REFERENCES}

Decker, Ryan; Haltiwanger, John; Jarmin, Ron and Miranda, Javier. “The Role of Entrepreneurship in US Job Creation and Economic Dynamism." Journal of Economic Perspectives, Summer 2014, 28(3), pp. 3-24; https://doi.org/10.1257/jep.28.3.3.

Gabaix, Xavier. "Power Laws in Economics: An Introduction." Journal of Economic Perspectives, Winter 2016, 30(1), pp. 185-206; https://doi.org/10.1257/jep.30.1.185.

Gourio, François and Roys, Nicolas. "Size-Dependent Regulations, Firm Size Distribution, and Reallocation." Quantitative Economics, July 2014, 5(2), pp. 377-416; https://doi.org/10.3982/QE338.

Lucas, Robert E. Jr. "On the Size Distribution of Business Firms." Bell Journal of Economics, Autumn 1978, 9(2), pp. 508-523; https://doi.org/10.2307/3003596. 
